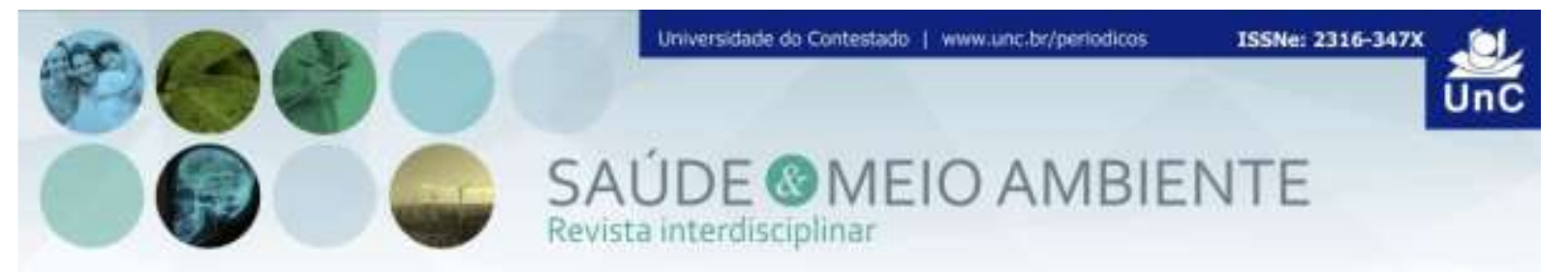

\title{
ESTUDO COMPARATIVO DAS NOTIFICAÇÕES DA VIOLÊNCIA CONTRA A MULHER ANTES E DURANTE A PANDEMIA DO COVID-19 NO PLANALTO NORTE CATARINENSE
}

\section{COMPARATIVE STUDY OF VIOLENCE NOTIFICATIONS AGAINST WOMEN BEFORE AND DURING THE COVID-19 PANDEMIC IN THE NORTH CATARINIAN PLANALTO}

\author{
Eliz Cristine Maurer Caus ${ }^{1}$ \\ Jéssica Angelita de Andrade ${ }^{2}$ \\ Keithy Gabrielly John ${ }^{3}$ \\ Micheli Wojciechowski ${ }^{4}$ \\ Patrícia Munhoz ${ }^{5}$
}

\section{RESUMO}

A violência contra a mulher é reflexo das relações de poder que estruturam a sociedade moderna, na qual as desigualdades existentes entre homens e mulheres, forçam-nas a assumir posições de subordinação. Na pandemia do Covid-19, os protocolos de saúde recomendaram o isolamento social, que repercutiu em problemas sociais e deixaram a mulher exposta à violência doméstica. Assim questionou-se: qual a relação das ocorrências da violência doméstica contra a mulher no antes e durante a pandemia no Planalto Norte Catarinense? O objetivo geral foi conhecer a relação das ocorrências da violência antes e durante a pandemia. Realizou-se um estudo documental, descritivo, quantitativo, baseado no Sistema de Notificação de Agravos oficial acessados no site da Diretoria de Vigilância Epidemiológica estadual, na qual levantou-se as notificações dos 13 municípios da 25a Agência de Desenvolvimento Regional de março a junho de 2019 e o mesmo período de 2020. Os resultados apontam para uma redução $46,4 \%$ de casos (153 para 82 ), o problema atinge mais as mulheres entre 20 a 60 anos, com ensino médio, prevalece a agressão física. Destacase a violência autoprovocada, na qual a mulher convive com uma situação extremamente desgastante tanto física quanto psicologicamente, buscando acabar com seu sofrimento. Conclui-se houve diminuição da notificação de casos, que sugere dificuldade da vítima em buscar ajuda. Por isso há necessidade de um olhar diferenciado para o problema, com estratégias inovadoras e profissionais capacitados para o enfrentamento do problema.

Palavras Chave: Violência contra a mulher. COVID-19. Enfermagem.

${ }^{1}$ Mestre em Enfermagem. Docente da Graduação em Enfermagem da Universidade do Contestado, Campus Mafra. Santa Catarina. Brasil. E-mail: eliz.caus@professor.unc.br

${ }^{2}$ Graduanda de Enfermagem, Universidade do Contestado Campus Mafra. Santa Catarina. Brasil. Email: jeh angelita@hotmail.com

${ }^{3}$ Acadêmica do Curso de Enfermagem. Universidade do Contestado, Campus Mafra. Santa Catarina. Brasil. E-mail: keithy.john@aluno.unc.br

${ }^{4}$ Acadêmica do Curso de Enfermagem. Universidade do Contestado, Campus Mafra. Santa Catarina. Brasil. E-mail: micheli.wojciechowski@aluno.unc.br

${ }^{5}$ Acadêmica do Curso de Enfermagem. Universidade do Contestado, Campus Mafra. Santa Catarina. Brasil. E-mail: patrícia.munhoz@aluno.unc.br 


\begin{abstract}
Violence against women reflects the power relations that structure modern society, in which the existing inequalities between men and women, force them to assume positions of subordination. In the Covid-19 pandemic, health protocols recommended social isolation, which resulted in social problems and left women exposed to domestic violence. So it was asked: what is the relationship between the occurrences of domestic violence against women before and during the pandemic in the Planalto Norte Catarinense? The general objective was to understand the relationship between the occurrences of violence before and during the pandemic. A documentary, descriptive, quantitative study was carried out, based on the official Disease Notification System accessed on the website of the State Epidemiological Surveillance Directorate, in which notifications were collected from the 13 municipalities of the 25th Regional Development Agency from March to June 2019 and the same period in 2020. The results point to a $46.4 \%$ reduction in cases (153 to 82 ), the problem affects women between 20 and 60 years of age, with high school, physical aggression prevails. Selfprovoked violence stands out, in which women live with an extremely stressful situation, both physical and psychological, seeking to end their suffering. In conclusion, there was a decrease in the notification of cases, which suggests the victim's difficulty in seeking help. Therefore, there is a need for a different look at the problem, with innovative strategies and trained professionals to face the problem.
\end{abstract}

Keywords: Violence against women. COVID-19. Nursing.

\title{
1 INTRODUÇÃO
}

A violência contra a mulher é reflexo das relações de poder que estruturam a sociedade moderna. Diante da pandemia do Covid-19 que recomenda isolamento social, repercutiram problemas sócios econômicos como o desemprego, deixando a mulher suscetível à violência no ambiente doméstico.

A violência contra a mulher é um tema de grande preocupação mundial, pois causa danos à saúde individual e coletiva, e pode estar presente em todos os âmbitos da vida e se manifestar sob diferentes formas e inúmeras circunstâncias. ${ }^{1}$

É crescente, em vários países do mundo, o número de violência contra as mulheres e meninas. Além do aumento de tempo em convivência com o companheiro violento por conta do isolamento social e do desemprego gerado, principalmente nos empregos informais ou autônomos, essas mulheres enfrentam diversas dificuldades para acessar rede de apoio, levando-se em consideração que os serviços de saúde estão focados no atendimento a novos casos de COVID-19. Essa nova dinâmica familiar e social tem como consequência o aumento de situações de violência, porém, muitos casos não chegam ao conhecimento dos órgãos públicos, ficam encobertos pela subnotificação dos casos. ${ }^{2}$ 
A subnotificação neste cenário é gerada principalmente pela dificuldade de comunicação com os serviços de atendimento. Muitas mulheres não possuem acesso à tecnologia, e quando possuem, tem receio de utilizá-la por medo de serem descobertas pelo agressor. ${ }^{3}$

O desemprego para as mulheres durante a pandemia só agravou a sua inserção no mercado de trabalho. A desvalorização social do trabalho feminino é visível, pois, além de se dedicarem ao emprego, respondem pelos afazeres domésticos e o cuidado dos filhos. ${ }^{4}$ A chefia das famílias pelas mulheres é cada vez mais crescente, porém estas não possuem as mesmas oportunidades que os homens nesta posição, fazendo com que sua jornada tripla de trabalho não traga retorno financeiro suficiente para prover a família. Assim, em muitas situações, a mulher prefere se manter com seu parceiro, ainda que estes proporcionem situações violentas. ${ }^{4}$

Pressupõe-se que o isolamento social impeça a mulher de buscar ajuda diante da agressão de seu companheiro, questionando-se: qual a relação das ocorrências da violência doméstica contra a mulher ao antes e na vigência da pandemia do Covid19 no planalto norte catarinense?

Compreende-se como violência contra a mulher qualquer ato ou conduta que resulte em sofrimento físico, psicológico ou sexual; que cause lesões de qualquer natureza e extensão; que acarrete em danos morais e patrimoniais ou que resulte em morte; tendo como vítimas as mulheres. ${ }^{5}$

No mundo, uma a cada seis mulheres sofre violência doméstica; destas, $60 \%$ teve como autor o companheiro íntimo e a mulher corre oito vezes mais risco de sofrer violência em sua própria residência, que em outros locais. ${ }^{6}$

Assim, o fenômeno da violência contra a mulher tornou-se um desafio para a equipe multidisciplinar e para toda a abrangência do serviço de saúde. ${ }^{7}$

A relação entre a construção de gênero e a violência contra a mulher, compreende a naturalização da violência em seu perfil histórico, acompanhando toda a vida da mulher, trazendo opressão e submissão. ${ }^{8} \mathrm{Na}$ sociedade se esperam determinados comportamentos para homens e para mulheres, que como qualquer fato social, vem sendo construído ao longo do tempo e continua sendo reproduzida enquanto houver normalização desta visão estereotipada. ${ }^{9}$

Um marco importante no enfrentamento da violência contra a mulher foi a criação da Lei Maria da Penha, ao estabelecer medidas para proteção e assistência à vítima por meio da Lei $n^{\circ} 11.340$ de 7 de agosto de 2006. Dentre essas medidas, estão inclusas as medidas protetivas, que visam à segurança e integridade da mulher com o afastamento do agressor; o acolhimento em lares provisórios para a mulher e seus dependentes; além de várias ações de prevenção às violências. ${ }^{10}$

A violência de gênero é aquela sofrida pelo fato de ser mulher, sem distinção de raça, classe social, religião, idade ou qualquer outra condição, produto de um sistema social que subordina o sexo feminino. Essas desigualdades se formalizam e 
institucionalizam nas diferentes organizações privadas, grupos que constituem as sociedades. ${ }^{11}$

Compreende-se o patriarcado como o domínio do homem sobre a mulher e nessa perspectiva, a mulher é sempre comparada ao homem. As heranças do patriarcado trazem para as mulheres dificuldades em serem autoras da própria história, vivendo sempre à sombra do masculino. ${ }^{12}$

É importante que as vítimas de violência possuam uma percepção positiva sobre os serviços de apoio, para que relatem suas experiências e possam interferir na redução dos agravantes da violência para a saúde e sua condição de vida e tenha suas necessidades atendidas e garantidas sua segurança com base normativa. ${ }^{10}$

Os casos de violência são registrados no Sistema de Informações sobre Agravos de Notificação (SINAN), pela ficha específica de violência doméstica, sexual e/ou outras violências, disponibilizadas pelo Ministério da Saúde, subsidiando a construção de políticas públicas e o desenvolvimento de estratégias assistenciais. Entende-se que os serviços de saúde são essenciais na identificação dos casos, pois apresentam, em tese, uma cobertura e cuidado às mulheres, podendo acolher, identificar e notificar o caso antes de incidentes mais graves. Como forma de aumentar a sensibilização dos profissionais, pode ser realizada educação permanente, trazendo informações a quem presta assistência, pois em muitos casos, o profissional que atende a vítima, a encaminha a outro profissional que detém o conhecimento acerca do preenchimento da notificação, porém a constrange na expressão da situação vivida. ${ }^{13}$

Todas as forças pessoais e sociais têm papel importante na ruptura da violência, pois o auxílio que a pessoa recebe influencia no modo como ela avalia uma situação como estressora ou não, e na escolha das ferramentas que utilizará para lidar com a situação. ${ }^{6}$

As ações de competência de órgãos e instituições públicas possibilitam a construção de estratégias e contribuem para o "empowerment" das mulheres e na ruptura do ciclo da violência. ${ }^{10}$

O fenômeno da violência contra a mulher tornou-se um desafio para a definição, em especial do corpo de conhecimento específico e escopo redimensionado, da prática da Enfermagem dentro de uma equipe multidisciplinar pautada na prática baseada em evidências e na filosofia do cuidado centrado na usuária. ${ }^{7}$

Dessa forma, estabeleceu-se o objetivo geral de conhecer a relação das ocorrências da violência doméstica contra a mulher, antes e na vigência da pandemia do Covid-19 no Planalto Norte Catarinense notificada no Sistema de Informação de Notificação de Agravos - SINAN. 


\section{MATERIAL E MÉTODOS}

Trata-se de uma pesquisa quantitativa, na qual são coletados dados numéricos de uma determinada população, trazendo números e variáveis que se correlacionam e convergem para a compreensão da realidade estudada, possibilitando a análise de padrões comportamentais e se comprovem teorias. ${ }^{14} \mathrm{~A}$ abordagem descritiva traz a possibilidade de se analisar um determinado fenômeno e descrevê-lo, e o tipo documental pretende selecionar, coletar e analisar dados provenientes de materiais que se apresentam ainda sem tratamento analítico. ${ }^{15}$

A coleta de dados foi realizada na base de dados do SINAN, disponibilizados publicamente no site da Divisão de Vigilância Epidemiológica (DIVE/SC), que tem como objetivo a coleta e interpretação de dados individuais e coletivos, e a elaboração de estatísticas que promovam a melhoria nos âmbitos de saúde da população. ${ }^{16}$ Foram organizados os seguintes dados de interesse: número de casos, perfil demográfico e cultural das vítimas, identificação dos agressores e tipificação da violência, a partir das notificações de violência doméstica ocorridas no período de março a junho de 2019 e de 2020 (período da Pandemia do Covid-19).

Conforme o Plano Diretor de Regionalização/SC, a 25a Agência de Desenvolvimento Regional possui 376.993 habitantes distribuídos em 13 municípios que compõe a região, sendo: Bela Vista do Toldo 6.311 habitantes; Campo Alegre 11.974; Canoinhas 54.319; Irineópolis 11.155; Itaiópolis 21.556; Mafra 56.017; Major Vieira 8,048; Monte Castelo 8.280; Papanduva 19.218; Porto União 35.250; Rio Negrinho 42.106; São Bento do Sul 83.576 e Três Barras com 19.183 habitantes. A Rede de Atenção à Saúde Regional está organizada em 26 Unidades de Apoio de Referência. ${ }^{17}$

Foram investigadas $100 \%$ das notificações realizadas pelos municípios no SINAN, tendo como critério de inclusão ser violência sofrida por mulheres, independentemente da idade. Os dados foram ordenados, utilizando-se da estatística simples e o Excel para elaboração de tabelas, A análise foi realizada por meio da comparação, similaridade e contraposição à literatura consultada.

O projeto foi submetido ao Comitê de Ética da Universidade do Contestado, Mafra/SC conforme resolução do CNS n466/2012, e aprovado pelo Número 4.139.326.

\section{RESULTADOS}

Os resultados obtidos explicitam a realidade dos casos de violência doméstica contra a mulher nos municípios do Planalto Norte Catarinense de março a junho antes e durante a pandemia do Covid-19. 
Estudo comparativo das notificações da violência contra a mulher antes e durante a pandemia do COVID-19 no Planalto Norte Catarinense

Tabela 1 - Comparativo do número de casos de violência doméstica contra a mulher no SINAN, no período de março à junho de 2019 e 2020, na 25a ADR/SC

\begin{tabular}{l|c|c|c|c|c|c|c|c|c|c}
\hline \multirow{2}{*}{ Município } & \multicolumn{2}{|c|}{ Março } & \multicolumn{2}{c|}{ Abril } & \multicolumn{2}{c|}{ Maio } & \multicolumn{2}{c|}{ Junho } & \multicolumn{2}{c}{ Total } \\
\cline { 2 - 13 } & 2019 & 2020 & 2019 & 2020 & 2019 & 2020 & 2019 & 2020 & 2019 & 2020 \\
\hline $\begin{array}{l}\text { Bela Vista do } \\
\text { Toldo }\end{array}$ & - & - & - & - & - & - & - & - & - & - \\
\hline Campo Alegre & 2 & 2 & 6 & 2 & 4 & - & 2 & - & 14 & 4 \\
\hline Canoinhas & 4 & 5 & 7 & 2 & 4 & 4 & 4 & - & 19 & 11 \\
\hline Irineópolis & 1 & - & - & - & 1 & - & - & - & 2 & - \\
\hline Itaiópolis & 3 & 1 & 6 & 4 & 2 & 2 & 2 & 1 & 13 & 8 \\
\hline Mafra & 9 & 7 & 6 & 4 & 4 & 7 & 9 & 2 & 28 & 20 \\
\hline Major Vieira & - & 1 & - & 1 & - & 1 & - & - & 0 & 3 \\
\hline Monte Castelo & - & - & - & - & - & - & 1 & - & 1 & - \\
\hline Papanduva & 1 & 2 & - & - & - & - & 1 & - & 2 & 2 \\
\hline Porto União & 8 & 1 & - & 2 & 5 & 1 & 4 & - & 17 & 4 \\
\hline Rio Negrinho & 2 & 1 & 3 & 2 & 1 & 1 & 3 & - & 9 & 4 \\
\hline São Bento do & 12 & 2 & 10 & 4 & 4 & 4 & 5 & - & 31 & 10 \\
Sul & & & & & & & & & & \\
\hline Três Barras & 3 & 8 & 6 & 6 & 2 & 1 & 6 & 1 & 17 & 16 \\
\hline Total & 45 & 30 & 44 & 27 & 27 & 21 & 37 & 4 & 153 & 82 \\
\hline Fonte: Dados SINAN/DIVE/SC(2020) & & & & & & & \\
\hline
\end{tabular}

Fonte: Dados SINAN/DIVE/SC(2020)

Tabela 2 - Comparativo do número de violência doméstica contra a mulher no SINAN por faixa etária, no período de março á junho de 2019 e 2020 , na $25^{\mathrm{a}}$ ADR/SC

\begin{tabular}{l|c|c|c|c|c|c}
\hline & \multicolumn{2}{|c|}{ Menor de $\mathbf{1 9}$ anos } & \multicolumn{2}{c|}{$\mathbf{2 0}$ anos a $\mathbf{6 0}$ anos } & \multicolumn{2}{c}{ Mais de 60 anos } \\
\hline Município & 2019 & 2020 & 2019 & 2020 & 2019 & 2020 \\
\hline Bela Vista do Sul & - & - & - & - & - & - \\
\hline Campo Alegre & 10 & 1 & 4 & 3 & - & - \\
\hline Canoinhas & 13 & 3 & 6 & 8 & - & - \\
\hline Irineópolis & - & - & 1 & - & 1 & - \\
\hline Itaiópolis & 3 & - & 10 & 8 & - & - \\
\hline Mafra & 10 & 6 & 17 & 11 & 1 & 3 \\
\hline Major Vieira & - & 2 & - & 1 & - & - \\
\hline Monte Castelo & 1 & - & - & - & - & - \\
\hline Papanduva & 1 & - & 1 & 2 & - & - \\
\hline Porto União & 9 & 1 & 7 & 3 & 1 & - \\
\hline Rio Negrinho & 3 & 1 & 6 & 2 & - & 1 \\
\hline São Bento do Sul & 10 & - & 20 & 8 & 1 & 2 \\
\hline Três Barras & 8 & 6 & 8 & 10 & 1 & - \\
\hline Total & 68 & 20 & 80 & 56 & 5 & 6 \\
\hline
\end{tabular}

Fonte: Dados SINAN/DIVE/SC (2020). 
Tabela 3 - Comparativo do número de violência doméstica contra a mulher no SINAN por escolaridade, no período de março á junho de 2019 e 2020 , na $25^{\mathrm{a}}$ ADR/SC

\begin{tabular}{|c|c|c|c|c|c|c|c|c|c|c|c|c|c|c|c|c|c|c|c|c|c|c|}
\hline \multirow[t]{2}{*}{ Município } & \multicolumn{2}{|c|}{ Branco } & \multicolumn{2}{|c|}{$\begin{array}{l}\text { Sem } \\
\text { instru- } \\
\text { ção }\end{array}$} & \multicolumn{2}{|c|}{$\begin{array}{c}1^{\mathrm{a}} \text { a } 4^{\mathrm{a}} \\
\text { série } \\
\text { incom- } \\
\text { pleta }\end{array}$} & \multicolumn{2}{|c|}{$\begin{array}{c}4^{a} \text { série } \\
\text { comple- } \\
\text { ta }\end{array}$} & \multicolumn{2}{|c|}{$\begin{array}{c}5^{\mathrm{a}} \text { a } 8^{\mathrm{a}} \\
\text { série } \\
\text { incom- } \\
\text { pleta }\end{array}$} & \multicolumn{2}{|c|}{$\begin{array}{l}\text { E.F. } \\
\text { Com- } \\
\text { pleto }\end{array}$} & \multicolumn{2}{|c|}{$\begin{array}{c}\text { E.M. } \\
\text { Incom- } \\
\text { pleto }\end{array}$} & \multicolumn{2}{|c|}{$\begin{array}{l}\text { E.M. } \\
\text { Com- } \\
\text { pleto }\end{array}$} & \multicolumn{2}{|c|}{$\begin{array}{c}\text { E.S. } \\
\text { Incom- } \\
\text { pleto }\end{array}$} & \multicolumn{2}{|c|}{$\begin{array}{l}\text { E.S. } \\
\text { com- } \\
\text { pleta }\end{array}$} & \multicolumn{2}{|c|}{$\begin{array}{l}\text { Não se } \\
\text { aplica }\end{array}$} \\
\hline & 19 & 20 & 19 & 20 & 19 & 20 & 19 & 20 & 19 & 20 & 19 & 20 & 19 & 20 & 19 & 20 & 19 & 20 & 19 & 20 & 19 & 20 \\
\hline $\begin{array}{l}\text { Bela Vista } \\
\text { do Toldo }\end{array}$ & - & - & - & - & - & - & - & - & - & - & - & - & - & - & - & - & - & - & - & - & - & - \\
\hline $\begin{array}{l}\text { Campo } \\
\text { Alegre }\end{array}$ & - & - & - & - & - & - & 1 & - & 3 & 1 & 2 & 1 & - & 1 & 3 & 1 & - & - & 1 & - & 4 & - \\
\hline $\begin{array}{l}\text { Canoi- } \\
\text { nhas }\end{array}$ & 8 & 2 & - & - & 2 & - & 1 & - & 1 & 4 & - & - & 7 & 1 & - & 2 & - & - & - & 2 & - & - \\
\hline Irineópolis & 1 & - & - & - & - & - & - & - & - & - & - & - & - & - & - & - & - & - & 1 & - & - & - \\
\hline Itaiópolis & - & 2 & - & - & 1 & - & 2 & 1 & 4 & 1 & 1 & 1 & 1 & - & 2 & 3 & - & - & 1 & - & 1 & - \\
\hline Mafra & 1 & 9 & - & - & 2 & - & - & - & 12 & 2 & 1 & 1 & 5 & 2 & 3 & 3 & 2 & 1 & 1 & - & 1 & 2 \\
\hline $\begin{array}{l}\text { Major } \\
\text { Vieira }\end{array}$ & - & - & - & - & - & 1 & - & - & - & 1 & - & - & - & - & - & 1 & - & - & - & - & - & - \\
\hline $\begin{array}{l}\text { Monte } \\
\text { Castelo }\end{array}$ & - & - & - & - & - & - & - & - & 1 & - & - & - & - & - & - & - & - & - & - & - & - & - \\
\hline $\begin{array}{l}\text { Papan- } \\
\text { duva }\end{array}$ & - & 1 & - & - & - & - & - & - & 1 & 1 & - & - & - & - & - & - & - & - & 1 & - & - & - \\
\hline $\begin{array}{l}\text { Porto } \\
\text { União }\end{array}$ & 3 & 1 & - & - & - & - & - & - & 5 & - & - & - & 4 & - & 3 & 2 & 2 & 1 & - & - & - & - \\
\hline $\begin{array}{l}\text { Rio } \\
\text { Negrinho }\end{array}$ & 1 & - & - & - & - & - & - & 1 & 2 & 1 & - & - & 1 & - & 5 & 2 & - & - & - & - & - & - \\
\hline $\begin{array}{l}\text { São Bento } \\
\text { do Sul }\end{array}$ & 1 & - & - & - & 3 & 1 & 2 & 1 & 6 & - & 4 & - & 3 & - & 10 & 8 & 1 & - & 1 & - & - & - \\
\hline $\begin{array}{l}\text { Três } \\
\text { Barras }\end{array}$ & - & - & - & 1 & 2 & - & - & 3 & 8 & 3 & 1 & 1 & 1 & 5 & 5 & 3 & - & - & - & - & - & - \\
\hline Total & 15 & 15 & - & 1 & 10 & 2 & 6 & 6 & 43 & 14 & 9 & 4 & 22 & 9 & 31 & 25 & 5 & 2 & 6 & 2 & 6 & 2 \\
\hline
\end{tabular}

Fonte: Dados SINAN/DIVE/SC (2020). 
Estudo comparativo das notificações da violência contra a mulher antes e durante a pandemia do COVID-19 no Planalto Norte Catarinense

Tabela 4 - Comparativo do número de violência doméstica contra a mulher no SINAN quanto à tipologia, no período de março á junho de 2019 e 2020, na 25a ADR/SC

\begin{tabular}{|c|c|c|c|c|c|c|c|c|c|c|c|c|c|c|}
\hline \multirow[t]{2}{*}{ Município } & \multicolumn{2}{|c|}{$\begin{array}{l}\text { Violênci } \\
\text { a Física }\end{array}$} & \multicolumn{2}{|c|}{$\begin{array}{c}\text { Violência } \\
\text { Psicológica } \\
\text { / } \\
\text { Moral }\end{array}$} & \multicolumn{2}{|c|}{$\begin{array}{c}\text { Violênci } \\
\text { a } \\
\text { Tortura }\end{array}$} & \multicolumn{2}{|c|}{$\begin{array}{l}\text { Violênci } \\
\text { a Sexual }\end{array}$} & \multicolumn{2}{|c|}{$\begin{array}{c}\text { Violência } \\
\text { Negligência } \\
\text { / abandono }\end{array}$} & \multicolumn{2}{|c|}{$\begin{array}{c}\text { Violência } \\
\text { por } \\
\text { Intervençã } \\
\text { o Legal }\end{array}$} & \multicolumn{2}{|c|}{$\begin{array}{c}\text { Outras } \\
\text { Violência } \\
\text { s }\end{array}$} \\
\hline & 19 & 20 & 19 & 20 & 19 & 20 & 19 & 20 & 19 & 20 & 19 & 20 & 19 & 20 \\
\hline $\begin{array}{l}\text { Bela Vista } \\
\text { do Toldo }\end{array}$ & - & - & - & - & - & - & - & - & - & - & - & - & - & - \\
\hline $\begin{array}{l}\text { Campo } \\
\text { Alegre }\end{array}$ & 6 & - & - & - & - & - & 5 & - & 1 & - & - & - & 4 & 4 \\
\hline Canoinhas & 10 & 7 & 11 & 1 & - & - & 6 & - & 1 & - & - & - & 6 & 5 \\
\hline Irineópolis & 2 & - & 1 & - & - & - & - & - & - & - & - & - & - & - \\
\hline Itaiópolis & 12 & 8 & 9 & 5 & 1 & 1 & 1 & - & - & - & 2 & - & 6 & - \\
\hline Mafra & 17 & 8 & 15 & 8 & - & - & 2 & 5 & 1 & 1 & - & - & 13 & 8 \\
\hline $\begin{array}{l}\text { Major } \\
\text { Vieira }\end{array}$ & - & 2 & - & 2 & - & 1 & - & - & - & - & - & - & - & - \\
\hline $\begin{array}{l}\text { Monte } \\
\text { Castelo } \\
\end{array}$ & - & - & - & - & - & - & 1 & - & - & - & - & - & - & - \\
\hline $\begin{array}{l}\text { Papanduv } \\
\text { a }\end{array}$ & - & 2 & - & - & - & - & - & - & - & - & - & - & 1 & - \\
\hline $\begin{array}{l}\text { Porto } \\
\text { União }\end{array}$ & 17 & 3 & - & 1 & - & - & - & - & - & - & - & - & - & - \\
\hline $\begin{array}{l}\text { Rio } \\
\text { Negrinho }\end{array}$ & 4 & 4 & - & 1 & - & - & - & - & - & - & - & - & 1 & 1 \\
\hline $\begin{array}{l}\text { São Bento } \\
\text { do Sul }\end{array}$ & 11 & 10 & 4 & 1 & - & - & 2 & - & - & - & - & - & 21 & - \\
\hline $\begin{array}{l}\text { Três } \\
\text { Barras } \\
\end{array}$ & 8 & 5 & 5 & 3 & - & - & 2 & 1 & 1 & - & - & - & 10 & 4 \\
\hline Total & 87 & 49 & 45 & 22 & 1 & 2 & 19 & 6 & 4 & 1 & 2 & 0 & 62 & 22 \\
\hline
\end{tabular}

Fonte: Dados SINAN/DIVE/SC (2020). 
Tabela 5 - Comparativo do número de violência doméstica contra a mulher no SINAN por agente da agressão, no período de março á junho de 2019 e 2020, na 25a ADR/SC

\begin{tabular}{|c|c|c|c|c|c|c|c|c|c|c|c|c|c|c|c|c|c|c|c|c|}
\hline \multirow[t]{2}{*}{ Município } & \multicolumn{2}{|c|}{$\begin{array}{c}\text { Pai } \\
\text { Padrasto }\end{array}$} & \multicolumn{2}{|c|}{$\begin{array}{c}\text { Mãe } \\
\text { Madrasta }\end{array}$} & \multicolumn{2}{|c|}{ Cônjuge } & \multicolumn{2}{|c|}{ Namorado } & \multicolumn{2}{|c|}{ Filho } & \multicolumn{2}{|c|}{ Irmão } & \multicolumn{2}{|c|}{ Desconhecido } & \multicolumn{2}{|c|}{$\begin{array}{l}\text { Policial } \\
\end{array}$} & \multicolumn{2}{|c|}{$\begin{array}{l}\text { Própria } \\
\text { Pessoa }\end{array}$} & \multicolumn{2}{|c|}{ Outros } \\
\hline & 19 & 20 & 19 & 20 & 19 & 20 & 19 & 20 & 19 & 20 & 19 & 20 & 19 & 20 & 19 & 20 & 19 & 20 & 19 & 20 \\
\hline $\begin{array}{l}\text { Bela Vista } \\
\text { do Toldo }\end{array}$ & - & - & - & - & - & - & - & - & - & - & - & - & - & - & - & - & - & - & - & - \\
\hline $\begin{array}{l}\text { Campo } \\
\text { Alegre }\end{array}$ & 1 & - & 1 & - & 1 & - & - & - & - & - & - & - & 1 & - & - & - & 5 & 4 & 1 & - \\
\hline $\begin{array}{l}\text { Canoi- } \\
\text { nhas }\end{array}$ & 1 & - & - & - & - & - & 2 & 1 & 1 & - & - & - & - & - & - & - & 13 & 6 & 2 & - \\
\hline Irineópolis & 1 & - & 1 & - & - & - & - & - & 1 & - & 1 & - & - & - & - & - & - & - & - & - \\
\hline Itaiópolis & 2 & - & - & - & 1 & 1 & 1 & - & - & - & 1 & 1 & 1 & - & 2 & - & 6 & 4 & - & 2 \\
\hline Mafra & 2 & 2 & 1 & 1 & 3 & 5 & - & - & 1 & - & 3 & 1 & 3 & - & - & - & 13 & 8 & - & 1 \\
\hline $\begin{array}{l}\text { Major } \\
\text { Vieira }\end{array}$ & - & - & - & - & - & - & - & 1 & - & - & - & - & - & - & - & - & - & - & - & 1 \\
\hline $\begin{array}{l}\text { Monte } \\
\text { Castelo }\end{array}$ & - & - & - & - & - & - & - & - & - & - & - & - & - & - & - & - & - & - & 1 & - \\
\hline $\begin{array}{l}\text { Papan- } \\
\text { duva }\end{array}$ & - & - & - & - & - & 1 & - & - & - & - & - & - & - & - & - & - & - & 1 & - & - \\
\hline $\begin{array}{l}\text { Porto } \\
\text { União }\end{array}$ & - & - & - & - & - & 1 & - & - & - & - & - & - & 1 & - & - & - & 16 & 3 & - & - \\
\hline $\begin{array}{l}\text { Rio } \\
\text { Negrinho }\end{array}$ & - & - & - & - & 1 & 2 & - & - & - & - & - & - & 1 & - & - & - & 2 & 1 & - & 1 \\
\hline $\begin{array}{l}\text { São } \\
\text { Bento do } \\
\text { Sul }\end{array}$ & - & - & - & - & 2 & - & 1 & - & - & - & 1 & - & 1 & - & - & - & 22 & 7 & 4 & 2 \\
\hline $\begin{array}{l}\text { Três } \\
\text { Barras }\end{array}$ & - & - & - & - & 1 & - & - & 1 & 2 & 1 & - & 1 & - & - & - & - & 8 & 4 & 4 & 1 \\
\hline Total & 7 & 2 & 3 & 1 & 9 & 10 & 4 & 3 & 5 & 1 & 6 & 3 & 8 & - & 2 & - & 85 & 38 & 12 & 8 \\
\hline
\end{tabular}

Fonte: Dados SINAN/DIVE/SC (2020).

\section{DISCUSSÃO}

Dentre os municípios da $25^{a}$ ADR/SC a maior população em ordem decrescente é: São Bento do Sul seguido de Mafra, Canoinhas, Rio Negrinho, Porto União, Itaiópolis, Papanduva, Três Barras, Campo Alegre, Irineópolis, Monte castelo, Major Vieira e Bela Vista do Toldo.

Percebe-se a diminuição na notificação de casos em na grande maioria dos municípios da $25^{\mathrm{a}}$ ADR (exceto Major Vieira) na comparação entre o antes e após pandemia, o que não significa redução efetiva no número de casos de violência. Dados da segurança pública de vários estados brasileiros apontam para um aumento de denúncias de vizinhos, bem como de casos de feminicídio, dificultando à mulher pedir e buscar socorro diante a vigilância acirrada de seus agressores impostas pelas restrições de mobilidade para controle da disseminação do Covid-19. Além disso, os serviços de saúde diante os desafios impostos pela desconhecida pandemia do Covid19 restringiram os atendimentos programáticos, reduzindo o horário de funcionamento, concentrando esforços na vigilância de casos suspeitos e confirmados 
do Covid-19, dificultando o acesso aos usuários às ações preventivas e de promoção à saúde.

Convém ressaltar que alguns municípios não têm registros de casos de violência contra a mulher o que a princípio é visto como positivo, entretanto, além do mencionado anteriormente, é necessário analisar o comportamento do fenômeno da violência em uma série histórica, suspeitar de possível subnotificação relacionado à falta de estrutura do serviço de saúde, qualificação técnica para notificação, reconhecimento e abordagem à mulher nos casos de violência e/ou dificuldade da vítima em buscar ajuda.

De modo geral, houve diminuição das notificações de violência doméstica contra a mulher na maioria dos municípios da $25^{\mathrm{a}} \mathrm{ADR}$, aponta-se para Major Vieira que de nenhum registro em 2019 passou para 3 em 2020 com todas as recomendações relacionadas à Pandemia vigentes. Assim atribui-se a melhoria na organização e sensibilidade do serviço de saúde tendo em vista ser o segundo município da regional com o menor número de habitantes.

O maior número de pessoas habitam respectivamente as cidades de São Bento do Sul, Mafra, Canoinhas, Rio Negrinho, Porto União e Três Barras, sendo essa a mesma ordem dos municípios em termos de notificação de casos de violência doméstica contra a mulher em 2019, com empate entre Porto União e Três Barras e em 2020, a ordem modifica para Mafra, Três Barras, Canoinhas e São Bento do Sul, fato que supõe a sensibilidade do serviço de saúde em identificar e notificar, bem como na ocorrência de precariedade nas relações trabalhistas, desemprego, agravando as condições sócio econômicas de forma diferenciada em cada município repercutindo no ato de violência, (im)possibilidade de denúncia (dificultado pela Pandemia) e acesso aos serviços de saúde.

O perfil demográfico de maior ocorrência de violência é de mulheres entre 20 a 60 anos de idade, sendo mais incidente em ordem decrescente nos municípios de São Bento do Sul, Mafra, Três Barras e Canoinhas.

Da primeira infância à terceira idade, a mulher sofre em casa o calvário de sua condição feminina e assim a violência doméstica deixa uma marca profunda na vida dela, além, dessa barbárie silenciosa, repercutir em toda a sociedade. Cada injúria, xingamento, ameaça, coação, tapa, estupro ou morte de mulher devido à violência de gênero é um retrocesso civilizatório a ser combatido. ${ }^{18}$

Muitas mulheres não sabem o que pode ser feito, como ir até a delegacia ou como proceder em caso de violência. Muitas vezes a vítima mora em uma casa pequena, que não tem como usar o telefone, sem acesso à internet, sem poder falar para alguém o que está acontecendo, ou ligar para a polícia sem que o agressor ouça. ${ }^{19}$

Em contradição ao resultado da pesquisa, a Agência Eco Nordestina na matéria intitulada: um vírus e duas guerras: mulheres enfrentam em casa a violência doméstica e a pandemia do Covid-19, informa que a violência doméstica não diminuiu, ela está mais privada do que nunca. A mulher que vive com um agressor já vivia isolada, agora ela está praticamente em cárcere privado. ${ }^{20}$ 
Considerando-se como escolaridade baixa o ensino fundamental incompleto, têm-se 59 casos em 2019 e 23 em 2020 o estudo aponta uma redução de 61\%; como escolaridade média aquelas que completaram o ensino médio sendo, 62 em 2019 e 34 em 2020 com decréscimo de 45,1\%; e escolaridade maior àquelas com ensino superior incompleto ou concluído, tem-se 11 em 2019 e 4 em 2020 com redução de $63,6 \%$, ou seja, reduziu em todas as faixas etárias.

Em relação à escolaridade das vítimas, o resultado corrobora com outros estudos que apontam para um perfil comum, ou seja: predomínio de mulheres na faixa etária de 30 a 39 anos e ensino médio completo. ${ }^{21}$

O registro em branco ou ignorado de 15 casos tanto em 2019 como em 2020 quanto à escolaridade configura uma incógnita incômoda, pois se pode tratar de crianças, na qual se suspeita da interpretação do notificador uma vez que há a opção não se aplica para esses casos. De qualquer forma, a incompletude dos dados gera informações pouco fidedignas, o que interfere na interpretação e análise do fenômeno da violência e consequentemente na elaboração de estratégias para seu enfrentamento.

Em uma revisão bibliográfica as mulheres vítimas de violência têm grau de escolaridade médio a superior completo, possuem algum tipo de ocupação, vivem em união estável, ou seja, mostra que qualquer mulher está propícia a sofrer uma violência sexual. ${ }^{22} \mathrm{~A}$ ocorrência da violência psicológica está presente na vida de mulheres mais jovens e com nível superior. ${ }^{23}$

Os resultados apontam que houve diminuição em praticamente todos os tipos de violência em comparação a antes da pandemia, mas a forma mais comum da manifestação da violência contra a mulher permanece a agressão física, seguida pela psicológica ou moral, outros tipos de violência, a sexual, a negligência ou abandono, a tortura com incremento de 1 caso em 2020.

Dessa forma, corrobora-se com outros estudos que mencionam a violência física como mais prevalente em pesquisas realizadas na Bahia ${ }^{24}$ e Piauí ${ }^{25}$.

O segundo tipo de violência mais notificado em 2019, e empatando com a violência psicológica/moral em 2020, é definida como Outras Violências. A ficha de notificação no item Tipo de Violência elenca várias tipologias passíveis de ocorrência, porém identificaram-se várias notificações preenchidas como Outras Violências, na qual não é possível identificar qual violência ocorreu ou se há dificuldade técnica no preenchimento das notificações. Em um estudo realizado com profissionais da saúde, dos entrevistados, $26,3 \%$ não compreendia a notificação e $61,4 \%$ não se sentiam capacitados para realizar o preenchimento da mesma. ${ }^{26}$

A maior redução, em termos percentuais, relacionada ao tipo de violência foram na negligência e abandono $(75 \%)$, a sexual $(68,4)$, outros tipos de violência $(64,5 \%)$ a psicológica ou moral $(51,1 \%)$ e agressão física $(43,6 \%)$, porém, convém ressaltar o número pequeno de 4 para 1 na ocorrência de negligência ou abandono por exemplo, traz uma interpretação equivocada. Porém, salienta-se a dificuldade que a mulher isolada no espaço domiciliar com seu companheiro possui para denunciar a violência sexual, e que muitas vezes, ela mesma não percebe como violência devido à opressão 
que a desigualdade de gênero lhe impõe. Além disso, a mulher impedida de frequentar a unidade de saúde devido à pandemia, fica mais distante da informação, da rede de apoio, do empoderamento e tomada de decisão para sair daquela situação de risco.

A violência física teve menor redução e, portanto, consta-se que esse é o tipo de violência mais incidente e mais reconhecida pela mulher, e que motivada pelo dano físico força-a a procurar o pronto atendimento e consequente na notificação no SINAN.

Dentre os tipos de violência sofrida pela mulher, a psicológica é constantemente subnotificada, pois ela pode estar comumente presente concomitantemente às demais violências e ser à base da violência doméstica, possui menor visibilidade, principalmente pela ausência de marcas físicas que denunciem à situação em que à mulher se encontra. Dessa forma, suspeita-se que a mulher em isolamento social tenha mais dificuldade em denunciar a violência psicológica a que está sujeita. As principais consequências deste tipo de violência são à depressão e o estresse pós-traumático, além de outras complicações psicológicas. ${ }^{27}$

Dentre os agentes da agressão estão à própria mulher, seus parceiros íntimos atuais ou de relacionamentos passados, pai/padrasto, mãe/madrasta e outros. Nos discursos de homens autores de violência contra suas parceiras, evidenciou-se que a causa associada à violência infringida à mulher se baseia principalmente em questões de construção dos papéis de gênero. As brigas que resultaram em agressão, muitas vezes, devem-se a traição realizada pelo companheiro, justificadas por alguns discursos como algo inerente ao sexo masculino, além da imposição às mulheres da permanência no lar, dedicando-se exclusivamente aos filhos e afazeres domésticos. ${ }^{28}$

No período houve uma diminuição de $55,3 \%$ no número de violência autoprovocada. Há uma estreita relação entre a violência autoprovocada e a tentativa de suicídio relacionada à violência doméstica sofrida pelas mulheres. A mulher que sofre violência doméstica convive com uma situação extremamente desgastante tanto física quanto psicológica. Percebe-se que a tentativa de suicídio está relacionada principalmente em acabar com o sofrimento vivenciado, e não diretamente com o desejo de morrer. Muitas mulheres convivem com a depressão, além da baixa autoestima e sentimento de dor emocional intensa, relacionada às diversas violências as quais são submetidas. ${ }^{29}$

Estudo aponta que no discurso de mulheres, há submissão das vítimas em relação ao seu cônjuge, acatando as suas ordens para evitar que ele seja mais violento, reforça os preceitos de que a violência doméstica contra a mulher se sustenta na imposição do patriarcado, pois essa dominação demonstrada pelos companheiros das vítimas tem relação com a sensação de poder. ${ }^{30}$

\section{CONCLUSÃO}

Conclui-se que a Pandemia do Covid-19 interferiu no número de notificações da violência doméstica contra a mulher em relação mesmo período anterior à mesma 
Planalto Norte Catarinense notificada no Sistema de Informação de Notificação de Agravos SINAN. Houve diminuição das notificações, mas não se pode afirmar que houve diminuição das ocorrências das violências.

A violência contra a mulher está presente nos municípios do estudo e os registros mostram redução, porém consideramos que os dados que vieram à tona são dos casos mais graves, na qual o serviço procurado foi emergencial. Devido às restrições da pandemia acreditamos que houve subnotificação pela dificuldade de acesso motivada pelo impedimento do agressor ou pelo medo do Covid-10.

Consideramos a necessidade de dar continuidade aos estudos, ampliando os dados das notificações buscando a série histórica do fenômeno da violência doméstica contra a mulher incluindo o período da pandemia relacionando os dados do SINAN ao sistema de informação da Segurança Pública.

\section{REFERÊNCIAS}

1. Menezes P R M, Lima I S, Correia C M, Souza S S, Erdmann A L, Gomes N P. Enfrentamento da violência contra a mulher: articulação intersetorial e atenção integral. Saude soc. [Internet]. 2014. Set [citado 2020 Nov 20] ; 23( 3 ): 778-786. Doi: https://dx.doi.org/10.1590/S0104-12902014000300004.

2. Brasil. ONU Mulheres. Violência contra as mulheres e meninas é pandemia invisível, afirma diretora executiva da ONU Mulheres. [Internet] 2020a. [citado 2020 Nov 25] Disponível em: http://www.onumulheres.org.br/noticias/violenciacontra-as-mulheres-e-meninas-e-pandemia-invisivel-afirma-diretora-executivada-onu-mulheres/.

3. Campos B, Tchalekian B, Paiva V. Violência contra a mulher: vulnerabilidade programática em tempos de SARS-COV-2/ Covid-19 em São Paulo. Psicologia \& Sociedade[Internet]. 2020. [citado 2020 Nov 25] ; 32: e20015. Disponível em: https://www.scielo.br/pdf/psoc/v32/1807-0310-psoc-32-e020015.pdf\&gt

4. Piosiadlo L C M, Fonseca R M G S, Gessner R. Subalternidade de gênero: refletindo sobre a vulnerabilidade para violência doméstica contra a mulher. Esc. Anna Nery [Internet]. 2014 Dec [cited 2020 Nov 23] ; 18( 4 ): 728-733. Doi: https://doi.org/10.5935/1414-8145.20140104.

5. Instituto Maria da Penha (Brasil). O que é violência doméstica: mitos da violência doméstica. [Internet] 2020. [citado 2020 Dez 05] Disponível em:

https://www.institutomariadapenha.org.br/violenciadomestica/o-que-e-violenciadomestica.html. 
6. Costa L, Lordes R, Fraga D, Santana N, Bubach S, Leite F. Estratégias de enfrentamento adotadas por mulheres vítimas de violência. Revista Enfermagem UERJ [Internet], 2018 [citado 2020 jul 04] ; 26: e19334. DOI: https://doi.org/10.12957/reuerj.2018.19334

7. Zanchetta M S, Guruge S, Oliveira R M P, Felipe I C V, Souto R Q. BrasilCanadá: lançando sementes através de consulta comunitária sobre o enfrentamento da violência contra a mulher. Esc. Anna Nery [Internet]. 2020 [cited 2020 Nov 26] ; 24( 3 ): e20190278. Doi: https://doi.org/10.1590/2177-9465ean-2019-0278.

8. Fernandes NC, Natividade CSJ. A naturalização da violência contra a mulher. Brazilian Journal of Development. 2020 out.; 6(10): 76076-76086,

9. Freitag RMK, Severo CG. Mulheres, linguagem e poder: estudos de gênero na sociolinguística brasileira. São Paulo: Blucher Open Access; 2015.

10. Souza T C C, Coelho A S F, Mattos D V, Valadares J G, Lima M R G, Costa P S et al. Características de mulheres vítimas de violência sexual e abandono de seguimento de tratamento ambulatorial. Cad Saúde colet, 2019 Jun ; 27(2):117123.

11. , Conselho Nacional da Justiça. Formas de violência contra a mulher. Disponível em: <http://www.cnj.jus.br/programas-e-acoes/lei-maria-da-penha/formas-deviolencia>. Acesso em: 05 mar. 2020.

12. Barradas, L.C.; Campos, A.C.R.; Oliveira, V.B.P. Violência doméstica contra mulheres: uma herança do patriarcado. IX Jornada Internacional de Políticas Públicas, Maranhão, v. 1, n. 1, p. 1-11, ago. 2019. Disponível em: <http://www.joinpp.ufma.br/jornadas/joinpp2019/images/trabalhos/trabalho_subm issaold_1450_14505cca3f662b892.pdf>. Acesso em: 25 nov. 2020.

13. Freitas RJM, Sousa VB, Costa T SC, Feitosa RMM, Monteiro ARM, Moura NA. Atuação dos enfermeiros na identificação e notificação dos casos de violência contra a mulher. hu rev [Internet]. 2018 jul. [citado 2020 nov 25];43(2):91-7. Disponível em: https://periodicos.ufjf.br/index.php/hurevista/article/view/2585

14. Esperón J M T. Pesquisa Quantitativa na Ciência da Enfermagem. Esc. Anna Nery [Internet]. 2017 [citado 2020 Nov 26] ; 21(1): e20170027. Doi: https://doi.org/10.5935/1414-8145.20170027..

15. Matias-Pereira J. Manual de metodologia da pesquisa científica. (4 ed). São Paulo: Atlas; 2019.

16. Brasil. Diretoria de Vigilância Epidemiológica (DIVE/SC) [Internet]; 2020b. [Acesso em: 2020 out 14]; 2020b. Disponível em:

<http://www.dive.sc.gov.br/index.php/dive>.

17. Santa Catarina. Plano Diretor de Regionalização. Gerência de Planejamento do SUS. Florianópolis; 2018. 
18. Bernardes $A H M$, Mader H, Fortuna D. Das vítimas de violência doméstica, $7 \%$ são menores de idade. Correio Braziliense [Internet]; 2019 ago 04. [citado em 2020 set 07]. Disponível em: https://www.correiobraziliense.com.br/app/noticia/ cidades/2019/08/04/interna_cidadesdf,775349/das-vitimas-de-violenciadomestica-7-sao-menores-de-idade.shtml.

19. Assunção, C. Dados da violência contra a mulher não refletem a realidade, mas a dificuldade em registrar a denúncia [Internet]. 2020 abr. 26. [Acesso em: 2020 set. 09]. Disponível em: https://sp.bancarios.com.br/04/2020dados-da-violênciacontra-a-mulher-não-refletem-a-realidade,-mas-a-dificuldade-em-registrar-adenuncia.

20. Amazônia Real. Agência Eco Nordeste\#colabora. Portal Catarinas e ponte jornalismo. Um vírus e duas guerras. Mulheres enfrentam em casa a violência doméstica e a pandemia do Covid-19 [Internet]. 2020 jun 12. [Acesso em: 2020 nov. 09]. Disponível em: https://ponte.org/um-vírus-e-duas-guerras.Mulheresenfrentam-em-casa-a-violência- doméstica-e-a-pandemia-do-Covid-19.

21. Leite F M C, Bravim LR, Lima, EFA, Primo CC. Violência contra a mulher: caracterizando a vítima a agressão e o autor. Revista de Pesquisa Cuidado é Fundamental. 2015; 7(1):2181-2191.

22. Oliveira LAS, Leal SMC. Mulheres em situação de violência que buscaram apoio no centro de referência Geny Lehnen/RS. Enferm. Foco. 2016; 7(2): 78-82.

23. Siqueira VB, Leal IS, Fernandes FECV, Melo RA, Campos MEAL. Violência psicológica contra mulheres usuárias da atenção primária à saúde. Rev. APS. 2018; $21(3): 437-449$.

24. Dantas GSV, Siva PL, Silva JK, Rios MA Caracterização dos casos de violência física contra mulheres notificados na Bahia. Arquivo Ciência Saúde. 2017 dez.; 4(24):63-68. Doi.org/10.17696/2318-3691.24. 4.2017. 878.

25. Madeiro A, Rufino AC, Sales IC, Queiroz LC. Violência física ou sexual contra a mulher no Piauí, 2009-2016. J. Health BiolSci; 2019 Set.; 3(7):258-264. Doi: http://dx.doi.org/10.12662/2317-3076jhbs.v7i3.2417.p258-264.2019

26. Cruz NPS et al. Preenchimento da Ficha de Notificação Compulsória de Violência Interpessoal e Autoprovocada: desafios enfrentados pelo profissional de saúde. HUMANAE: Questões controversas do mundo contemporâneo. 2019 Jan.;13(2):1-16.

27. Fontes, G.C. A (in) visibilidade da violência conjugal psicológica contra a mulher na produção científica brasileira em psicologia; 2017. 106 f. Dissertação

(Mestrado) - Curso de Psicologia Clínica e Cultura, Departamento de Psicologia Clínica -PCL, Universidade de Brasília -Unb, Brasília - DF, 2017. Disponível em: $<$ https://repositorio.unb.br/bitstream/10482/31341/1/2017_GiordanaCalvaoFonte sSantanadeOliveira.pdf>. Acesso em: 23 nov. 2020. 
28. Silva AF, Gome NP, Pereira A, Magalhães JRF, Estrela FM, Sousa AR, Carneiro, J B Atributos sociais da masculinidade que suscitam a violência por parceiro íntimo. Rev Bras de Enferm; 2020 fev.; 73(6) 1-7. Doi: https://doi.org/10.1590/0034-7167-2019-0470.

29. Correia C M, Diniz NMF, Gomes NP, Andrade ICS, Campos LM, Carneir JB Sinais de risco para o suicídio em mulheres com história de violência doméstica. SMAD, Rev. Eletrônica Saúde Mental Álcool Drog.; 2018; 4(14): 219-225. Doi: http://dx.doi.org/10.11606/issn.1806-6976.smad.2018.151401.

30. Silva DRQ, Torman MR. "Em briga de marido e mulher", metemos a Colher: grupos terapêuticos com mulheres em situação de vulnerabilidade e violência de gênero. Periódico do Núcleo de Estudos e Pesquisas Sobre Gênero e Direito Centro de Ciências Jurídicas-Universidade Federal da Paraíba; 2018 jan.; 7(3):22-42. Disponível em: <https://periodicos.ufpb.br/index.php/ged/article/view/ 43002/21407>. Acesso em: 09 nov. 2020.

Artigo recebido em: 08/12/2020

Artigo aprovado em: 20/03/2021

Artigo publicado em: 26/04/2021 